\title{
Development of Ethnic Social Identity Among the Members of Ethnic Community Organizations as the Factor of Preventing the Spread of Nationalist Sentiments in a Multicultural Society
}

\author{
Tatiana Ivanovna Bonkalo ${ }^{1}$, Olga Borisovna Polyakova ${ }^{1}$, \\ Sergey Vasilievitch Bonkalo ${ }^{1}$, Natalya Tarasovna Kolesnik ${ }^{2}$ and Elena \\ Alexandrovna Sorokoumova ${ }^{3}$ \\ ${ }^{1}$ State Russian Social University \\ ${ }^{2}$ Moscow Region State University \\ ${ }^{3}$ Moscow State Pedagogical University
}

DOI: http://dx.doi.org/10.13005/bbra/1912

(Received: 04 August 2015; accepted: 21 September 2015)

\begin{abstract}
This article is dedicated to the actual problem of preventing the spread of nationalist sentiments in a multicultural society. The modern stage of social development characterized by rapid growth of inter-ethnic contact, intense changes in the ethnic composition of the country, which explains kept in repair by dynamics of migration flows, a variety of social groups, ethnic communities. In this regard, the issue of ethnic minorities, their social status and their position in the multinational country, their successful adaptation and integration into the global multicultural region, has acquired a special urgency. Basing on the conducted empirical study, the authors make the conclusion about the development of ethnic social identity of the members of ethnic community organizations as the key condition for preventing of the spread of neo-nazism. The authors define the nature, content and types of ethnic social identity of national minorities, elaborate the author diagnostic tools to study its development, conduct the empirical research and basing on its results discover the psychological mechanisms for transformation of national identity of representatives of different ethnic groups dispersedly residing on the territory of Russian.
\end{abstract}

Key words: ethnic identity, social identity, ethnic social identity, national minorities, ethnic community organizations.

\section{The relevance of the research problem}

The current stage of social development has been characterized by a rapid growth of interethnic contacts, the intensive changes in the ethnic composition of the countries due to the dynamics of constantly renovating migration flows, the variety of the represented social groups as ethnic communities.

In connection with this the problems of ethnic minorities, their social status and peculiarities of their position in a multicultural country, their adaptation and the successful

\footnotetext{
* To whom all correspondence should be addressed.
}

integration into the world multicultural area, have acquired the special relevance. Solving these issues predetermines in a large part the efficiency of realization of democratic ideas and achieving of national unity and social safety which would guarantee the liberty of each member of the society. According to the principles proclaimed by the UN Charter, the basis for the liberty, justice and global peace would be the recognition of the equal and inalienable rights of every person, regardless of his or her race or ethnicity.

However, the negative consequences of globalization have led to the complication of the existing social, economical and political problems: disproportion among the ethnic groups' membership, marginalization, ethnophobia, 
xenophobia, chauvinism, ethnocentrism which result in the growth of inter-ethnic tension and conflicts. It will suffice to mention the inter-ethnic conflicts in Great Britain (Northern Ireland), Spain (the Basques and the Catalans), France (the Bretons and Corsicans), Canada (Quebec), Middle East (the Arab-Israeli conflict), China (Xinjiang Uygur Autonomous Region), North and South Koreas, Sudan (North and South Sudan), US (immigrants from Latin America), Occidental Europe (African and Asian immigrants), Ukraine, Azerbaijan, Armenia, Moldova and other countries of the former Soviet Union, and, finally, in Russia, to outline the scale of the problem of the ethnic component of social and civil relations. In connection with the intensive growth of inter-ethnic tension it has become of greater significance not only for the world community in the whole, but also for Russian society in particular, the creation and conducting of the harmonious relationship with representatives of various ethnic groups and ethnic communities.

With this purpose in the late 1980's beginning of 1990's in Russia and abroad ethnic community organization began to appear; participating in their activities has ensured the satisfaction of the substantial personal need in preservation and maintenance of the ethnic "Self" of their members, which is determined by the developmental peculiarities of the ethnic selfconsciousness and ethnic identity.

As known, the basic activity of the ethnic community organizations is aimed to the revival, preservation and development of the original culture, traditions and customs of a particular ethnic group, its national language, arts crafts and popular art.

However, with the increasing migration flows and the inter-ethnic tension the ethnic community organizations, forming one of the key elements of the structural organization of civil society, are called upon to perform not only the educative and socializing functions, but also the function of formation of social positioning stand among the members, helping them to adapt to the new living conditions in another ethnic and cultural environment, strengthening the public order and ensuring the optimal inter-ethnic relationship.

Dysfunctional activities of ethnic community organizations may lead to the most serious negative consequences, actualizing the risks of open inter-ethnic confrontations and conflicts.

\section{The level of development of the problem}

The results of inter-discipline analytical research have evidenced that the modern psychological science does not possess any system knowledge about the peculiarities of functioning of the ethnic community organizations and the specifics of their management.

Ethnic, national and cultural community organizations and communities have become the object of researches mostly in the political (Belozerova, 2013 etc.), historical (Sadovoy, 1998 etc.) and sociological (Skobelina, 2005 etc.) sciences.

The researches study the problems of ethnical minorities: their discrimination (Yuriev, 2000), intercultural adaptation (Buchek, 2012), social status (Kurinskyh, 2013), typology and classification (Zdravomislov, 1996), functionality and basic activities of the ethnic community organizations and ethnic communities (Tishkov and Shabaev, 2011).

The researches in the field of ethnopsychology (Gumilev, 1992; Krysko, 2002; Stefanenko, 2008) have been mostly dedicated to the question of ethnical identity: its nature (Alexandrenkov, 1996; Stefanenko, 2008; Baklushinsky and Orlova, 1998 and others), types and factors (Bonkalo, Kolesnik and Varavina, 2015), stages of formation (Lebedeva, 1999, Stefanenko, 2008), dynamics and variability in the times of crucial social changes (Bromley, 2008; Soldatova, 1997; Pochebut, 2005). The peculiarities of ethnic identity have been studied through the example of various nationalities (Miller, 1995; Tishkov and Shabaev, 2011), including the indigenous minorities (Drobizheva, 2005 and others).

Despite the focused attention of the scientists to the issues of ethnic identity, in the modern science there are practically no system researches of ethno-civil identity of national minorities. With this the results of such research would become the theoretical and methodology base for elaboration of the efficient preventive programs aimed to preservation of national safety of multicultural countries, prevention of deformation process in national self-identification of its members, i.e. transformation of natural sense of patriotism into nationalism. 
Activization of the unions of representatives of different ethnic groups into the correspondent ethnic community organizations during the last decades, on the background of transformation of modern society and its transmission from social to a personal paradigm, has been due to the crisis of personal value consciousness which determines the increasing ethnic self-consciousness of an individual and concentration of its attention on personal problems, necessities and interests.

To realize the potential of ethnic community organizations in the building of civil society it is necessary that its members should feature the high level of development of civil identity and civil responsibility, which implies incorporation of this objective into the priority areas of activity of the ethnic community organizations.

\section{Methodology}

This study has engaged the complex of methods: theoretical (analysis of literature, synthesis of basic methodological approaches, systematization, abstracting, modeling), empirical (observation, semi-structured interviewing, questionnaire, testing, projective methodics, expert evaluation, experiment) and statistical (calculation of arithmetical mean, standard deviation, representative error, Student's t-test, $\div^{2}$-criterion, correlation analysis, analysis of variance, factor and cluster analysis).

The empirical study has required the methodics aimed to reveal the peculiarities and the degree of manifestation of ethnic identity of an individual, as well as the author's questionnaires and diagnostics methodics: Questionnaire form of self-identification of a national representative, Questionnaire form "Language as the basis for preservation and development of national minority identities" and the Projective methodics pictogram) - "Externalization of national self-identification of national minorities", methodology for the identification of types of ethnic tolerance, the methodology to determine the level of development of civic responsibility, the methods of examination of the features of ethno-civil identity. All the above methodics have undergone the procedures of validation and approbation.

The empirical study included several series, each of which has had its purpose, objectives, organizational and methodological support and the research samples.

Firstly, the study was concentrated on the peculiarities of ethnic identification of various ethnic groups, dispersedly residing on the territory of Russian Federation. With the purpose to conduct this series of empirical studies there were formed six research samples, each of which included representatives of the Germans, the Jews, Slavic people, and the people of the North Caucasus (Chechens, Ingush, Circassians, Dagestanis, Ossetians), Transcaucasus (Armenians, Azerbaijanis, Georgians, Adjarians, Abkhazians), and the indigenous populations of Russia (Kalmyk, Nenets, Tuvinians, Udegei, etc.). The research samples of interviewees have been balanced in characteristics of number $(n=160)$, and social and demographical (sex (80 women against 80 men) and age $(37,8)$ ).

Secondly, the same research sample was used to study the peculiarities of development of ethno-civil identity of representatives of various national minorities - members of ethnic community organizations - with implementation of the questionnaire "Ethno-civil identity".

Thirdly, the questionnaires and the subsequent interviews were used to study the peculiarities and specific relations with native population of the representatives of Caucasus, Central Asia and North Caucasus, who had immigrated in Russian Federation. 178 members of ethnic groups took part in this series of empirical study.

In the final series of the empirical study the obtained empirical data were subject to a correlation analysis, the results of which allowed us making some conclusions in connection with the degree of correlation between the type of ethnocivil identity of the members of ethnic community organizations and the level of development of interethnic intolerance as an indicator of possible expansion and preservation of neo-nationalist ideas and sentiments. For this purpose there was used the questionnaire developed by T.I. Bonkalo and L.V. Varavina, modified in accordance with the subject of our study.

\section{RESULTS}

The results of the study of types and degree of manifestation of ethnic identity in representatives of national minorities - members 
of ethnic community organizations

It is of interest the results of the study of types (Table 1) and the degree of manifestation of ethnic identity in the interviewees of the six research groups.

Thus, it has been discovered that the percentage distributions for the degree of manifestation of ethnic identity have differed one from the another at the significant difference level $\left(\div^{2}=244,38, \mathrm{p}<0,01\right)$. In the whole, the high level of manifestation of ethnic identity has been registered in representatives of populations of North Caucasus and low-numbered people of the North, whereas the low level - in most representatives of the German, the Jews, and Slavic people.

This fact may evidence that the process of ethnic self-identification is being significantly influenced by socio-cultural facts - the peculiarities of socio-cultural development of the ethnic group, the history of residence of its representatives on the territory of a foreign country, their political and economical situation, the presence or absence of restrictions.

The types of ethnic identity in various ethnic groups shall also be different (Table 1). With this it is necessary to note that the vast majority of the interviewees are still characterized by a positive

Table 1. The results of research of the types of ethnic identity in the interwiees of the six research groups

\begin{tabular}{lllllll}
\hline $\begin{array}{l}\text { Type of ethnic } \\
\text { identity }\end{array}$ & $\begin{array}{l}\text { The } \\
\text { German }\end{array}$ & $\begin{array}{l}\text { The } \\
\text { Jews }\end{array}$ & $\begin{array}{l}\text { Slavic } \\
\text { people }\end{array}$ & $\begin{array}{l}\text { North } \\
\text { Caucasus }\end{array}$ & Transcaucasus & $\begin{array}{l}\text { People of } \\
\text { North }\end{array}$ \\
\hline Ethno-nihilism & $14,02 \pm 1,5$ & $14,32 \pm 1,5$ & $15,85 \pm 1,6$ & $6,89 \pm 0,7$ & $7,78 \pm 0,8$ & $5,68 \pm 0,6$ \\
Indifference & $18,27 \pm 1,9$ & $15,06 \pm 1,5$ & $18,64 \pm 1,9$ & $8,24 \pm 0,8$ & $11,18 \pm 1,1$ & $9,74 \pm 1,0$ \\
Positive EI & $12,32 \pm 1,3$ & $14,84 \pm 1,5$ & $17,98 \pm 1,8$ & $14,72 \pm 1,6$ & $16,34 \pm 1,7$ & $18,02 \pm 1,9$ \\
Ethno-egoism & $7,24 \pm 0,8$ & $5,38 \pm 0,6$ & $6,06 \pm 0,6$ & $11,02 \pm 1,2$ & $9,38 \pm 1,0$ & $6,86 \pm 0,7$ \\
Ethno-isolationism & $9,16 \pm 1,0$ & $13,73 \pm 1,4$ & $5,38 \pm 0,6$ & $8,96 \pm 0,9$ & $10,32 \pm 1,0$ & $6,36 \pm 0,6$ \\
Ethno-fanatism & $5,34 \pm 0,6$ & $4,12 \pm 0,4$ & $4,34 \pm 0,4$ & $9,64 \pm 1,1$ & $8,35 \pm 0,9$ & $2,08 \pm 0,2$ \\
\hline
\end{tabular}

Table 2. Results of the research of peculiarities of the development of ethno-civil identity in representatives of various ethnic groups

\begin{tabular}{|c|c|c|c|c|c|c|}
\hline $\begin{array}{l}\text { Type of ethnic } \\
\text { identity }\end{array}$ & $\begin{array}{l}\text { The } \\
\text { German }\end{array}$ & $\begin{array}{l}\text { The } \\
\text { Jews }\end{array}$ & $\begin{array}{l}\text { Slavic } \\
\text { people }\end{array}$ & $\begin{array}{l}\text { North } \\
\text { Caucasus }\end{array}$ & Transcaucasus & $\begin{array}{l}\text { People of } \\
\text { North }\end{array}$ \\
\hline Balanced & $4.48 \pm 0.5$ & $5,66 \pm 0,6$ & $6,14 \pm 0,7$ & $3,44 \pm 0,4$ & $6,64 \pm 0,8$ & $7,74 \pm 0,9$ \\
\hline Crisis & $4.16 \pm 0.4$ & $3,78 \pm 0,4$ & $2,88 \pm 0,3$ & $4,06 \pm 0,5$ & $3,24 \pm 0,4$ & $1,96 \pm 0,2$ \\
\hline Conformal & $4,98 \pm 0,6$ & $6,09 \pm 0,7$ & $6,66 \pm 0,7$ & $4,49 \pm 0,5$ & $2,96 \pm 0,4$ & $2,14 \pm 0,3$ \\
\hline Indifferent & $7,18 \pm 0,8$ & $7,74 \pm 0,8$ & $5,44 \pm 0,6$ & $1,28 \pm 0,3$ & $4,58 \pm 0,6$ & $3,24 \pm 0,4$ \\
\hline Conflictive & $4,06 \pm 0,4$ & $5,64 \pm 0,6$ & $2,76 \pm 0,3$ & $2,56 \pm 0,3$ & $3,98 \pm 0,5$ & $1,27 \pm 0,3$ \\
\hline Isolative & $3,28 \pm 0,4$ & $7,89 \pm 0,8$ & $1,98 \pm 0,3$ & $4,94 \pm 0,6$ & $4,76 \pm 0,5$ & $3,94 \pm 0,5$ \\
\hline
\end{tabular}

Table 3.The indexes of level of significance of differences in the choice of acculturation strategies by the immigrants of different ethnic groups

\begin{tabular}{lcl}
\hline Types of ethnic groups & Indexes , ${ }^{*}$ emp. & Indexes , ${ }^{*}$ cr. \\
\hline Dagestanians & 3,54 & 2,31 (significant at $1 \%$ level of significance) \\
Chechens & 5,00 & 2,31 (significant at $1 \%$ level of significance) \\
Ingush & 3,49 & 2,31 (significant at $1 \%$ level of significance) \\
Tajiks & 3,24 & 2,31 (significant at $1 \%$ level of significance) \\
Kirghiz & 3,78 & 2,31 (significant at $1 \%$ level of significance) \\
Uzbeks & 2,9 & 2,31 (significant at $1 \%$ level of significance) \\
Armenians & $-4,59$ & 2,31 (significant at $1 \%$ level of significance) \\
\hline
\end{tabular}


ethnic identity, that is, the combination of positive attitude to the native and "foreign" people.

However, the ethnic hypo-identity was generally characteristical in a greater extent for representatives of the German and Slavic peoples, while the hyper-identity - for the people of North Caucasus and Transcaucasus.

It should also be noted that the smallest positive identity, compared with other groups, has been registered in the groups of Germans and Jews. At the same time with the general background of rather high level of manifestation of hypo-identity in representatives of these groups, they feature the different types and differ significantly one from another in the terms of ethno-isolationism $(\mathrm{t}=2,24$, $\mathrm{p}<0,05)$ and ethnic indifference $(\mathrm{t}=2,08, \mathrm{p}<0,05)$. Pair-wise comparison of the indicators in question evidences that while many Jews have featured mostly the ethno-nihilism, that is, the negation of ethnicity in general and the search of sustainable interpersonal relationships on the basis of other social and psychological criteria, the Germans have featured the ethnic indifference, that is, the erosion of ethnic identity, the uncertainty of belonging to a particular ethnic group. It is also remarkable that in comparison with the common high indexes of hyper-ethnicity in the groups of North Caucasus and Transcaucasus, the groups of Germans and

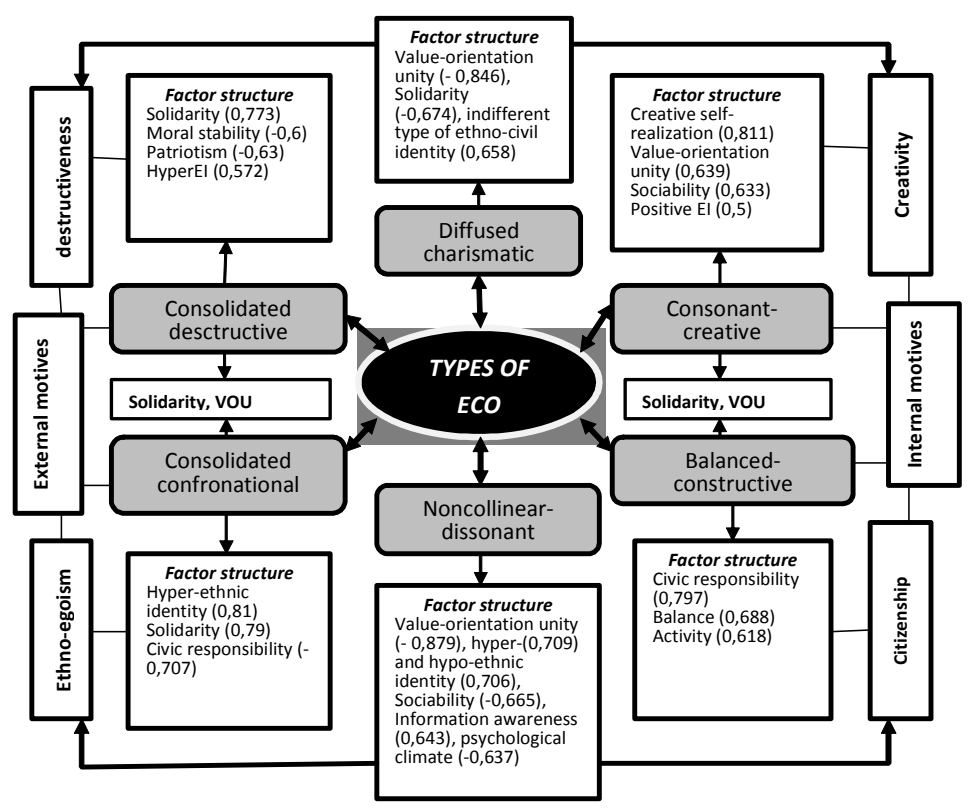

Fig. 1. Types of ethnic community organizations and their factor structures

Jews have featured rather high indexes in the scale of "ethno-isolationism", which evidences the existing belief in many of them in the superiority of their nation, in its unique and important historical mission.

Such contradictory data obtained in the process of express diagnostics, became a source of an in-depth study of the peculiarities of the process of ethnic identification within the different ethnic groups.

The application in this study of the projective methodics, and in particular, the author methodology "Pictogram", drawing tests, essays and short stories, questionnaires and interviewing, the subsequent content analysis and cluster analysis of the obtained empirical data, have helped to clarify the structure of ethnic identity and the content of its cognitive, affective, and behavioral components, the combination of which constitutes the substance of ethnically conditioned mental states of an individual.

The results of the study of peculiarities of development of ethno-civil identity in representatives of different ethnic groups - the members of ethnic community organizations

Apart from this, in the research groups of the first series of empirical studies we studied the characteristics and degree of manifestation of civil 
identity, understood as a perception of oneself as a citizen of the Russian Federation, the attitude to this fact and the subjective experience. To explore the civil identity there were developed and approved the specialized questionnaires, reflecting the level of development of patriotism, the sense of homeland and attitude to the fact of one's residence on the territory of Russia, which had passed the psychometric tests for its validity and reliability.

As a result of qualitative and quantitative processing of the research data, there have been identified the six types of ethno-civil identity as indicators of the peculiarities of personal experience in connection with the belonging to a certain ethnic group, on the one hand, and with the fact of residence on the territory of Russia, on the other.

With this the ethno-civil identity has been presented as a holistic new formation of an individual, reflecting its ability and willingness to preserve and enrich the culture of one's own nation as well as the national identity of other people of modern Russia, as a whole, and its prosperity as a multinational country.

The ethno-civil identity as a synthesis of ethnic and civil identities, is expressed through the integration, unity and entirety of self-identity of an individual as the representative of a certain ethnic group and the transmitter of its national values and culture, and, at the same time, as the citizen of a multiethnic society, who shall be guided by the sense of love for its country and pride for being the part of it. Such synthesis shall be possible upon the integration by an individual of human values and priorities, adopting of the diversity of socio-cultural attitudes, norms and forms of behaviour and activities.

Thus, the combination of ethnic and civil identities, the attitude and subjective experience in connection with one's place and position in the society, which determine the relevant psychological and emotional state and behaviour of an individual, are forming the internal content of the isolative (type of an immigrant means the perception of oneself as a forced and temporary migrant), conflictive (non-separated civil and ethnic identities, the simultaneous perception of oneself as a Russian and as a representative of another ethnic group), indifferent (failure to recognize the importance of ethnic component in the life of an individual), conformal (complete rejection of one's ethnicity), crisis (uncertainty of one's perception as a representative of one or another ethnic groups) and balanced (balance and distinction of belonging to an ethnic group and of being a citizen of Russia) types of ethno-civil identity.

Basing on the results of the cluster analysis there have been elaborated the author questionnaire allowing determining the type of ethno-civil identity of an individual.

The results of research undertaken with this author questionnaire in the whole have confirmed the preliminary conclusions and have evidenced that the balanced type of ethno-civil identity has been characteristical to a very small number of representatives of various ethnic groups (Table 2).

Most of the interviewees have featured an unharmonious combination of ethnic and civic identities, which stipulates the need and expediency of developing the special programs aimed to providing of the efficient psychological support to the national minorities in process of their ethnic and civil identification.

Results of research of the peculiarities of attitude of immigrants from Central Asia, Northern Caucasus and Transcaucasus - the members of ethnic community organizations - to the native population of Russia

First of all, there should be mentioned a lower educational level and professional skills of youth workers from Central Asia (Tajiks, Uzbeks, and Kyrgyz) than that of the immigrants from Transcaucasus and the Northern Caucasus. Thus, according to the analysis, $71,4 \%$ of immigrants from the Central Asia have featured the incomplete secondary education (9-10 grades); $14.3 \%$ of respondents have had the completed higher education, and another $14.3 \%$ have completed the 6-7 classes of a secondary school. Of the overall amount of the interviewed immigrants of these ethnic groups $-28.6 \%$ of respondents have had no profession; the same amount $(28,6 \%)$ have been working previously as shepherds, i.e. they did not practically study in any secondary (or primary) professional institution; and $14.3 \%$ have had the completed higher education.

At the moment the immigrants from Central Asia are mainly working in the construction industry (non-qualified work), in the sector of 
municipal services (street cleaning, landscaping, etc.), in the trade (cashiers, maintenance workers etc.).

The main motive for migration (permanent as well as temporary) of $93 \%$ of representatives of the above ethnic groups shall be improvement of their financial situation ("earnings"); $7 \%$ of respondents have mentioned such motive as «helping parents» and another $7 \%$ of immigrants have indicated not only earnings but also the uncomfortable national policy in their republic (for example, the national policy in Turkmenistan against the Uzbeks). After filling out the questionnaires we have arranged interviews with each of the respondents, and specifying the motives for migration it should be added that many of the immigrants are not only trying to increase their earnings but also helping their families in the homeland.

The question about the place of living in Moscow and Moscow region was answered as follows: "renting a flat" - 35,7\% of respondents; $42,9 \%$ of immigrants have been living in dormitories and $21,4 \%$ in the place of work (for instance, at the construction site).

It is notable that around $30 \%$ of immigrants from Central Asia have featured a so called «trial migration» - they have not decided yet how much time they were going to stay in Moscow region. 35,7\% of respondents have indicated that they had come for $1-2$ years; $14,3 \%$ of immigrants arrive to work in Moscow region every summer and the same number $(14,3 \%)$ have said that they had arrived in Moscow for permanent residence.

However, it should be noted that the actual situation with residence (permanent or temporary) in Moscow region of Central Asia immigrants is rather different. A large number of young immigrants after having established in Moscow and Moscow region go back to their ethnic homeland, get married and bring their families to the Moscow region. According to statistical data, Moscow region has featured the increased number of children born in the families of immigrants from Central Asia.

To the question about the specifics of attitude of native population to the immigrants following answers have been given: "good attitude" - according to $57,2 \%$ of respondents; "supportable" - 21,4\% of respondents; "bad" - 7,1\% of respondents and "no communication" - 14,3\%.

The question about their attitude towards the native population was answered as follows: the vast majority of immigrants (78,6\%) have indicated that their attitude was "good"; "supportable" - 7,1\% of respondents and 14,3 have mentioned they had "no communication" with native population.

Thus, the immigrants from Central Asia in general think that their attitude towards the native population was better than that of the receiving party towards them. Besides, around $15 \%$ of immigrants do not have contacts with native population.

Let us proceed to the analysis of questionnaires of immigrants from Transcaucasus (Armenians, Azerbaijanis, and Georgians) and, in particular, evaluate the data on their educational and professional level. It has been found that the total number of immigrants from these ethnic groups have featured a notable diversity of indicators of their educational and professional qualification. Thus, about $80 \%$ of Armenians have had the professional (vocational) education or higher education (students), the remainder have the completed secondary education. Similar picture was registered among the immigrants from Georgia. However, among the Azerbaijanis immigrants around $67 \%$ have the completed secondary education but no professional one (they have been working and agricultural sector or trade). The remaining number of Azerbaijanis immigrants has featured the completed secondary education together with the profession.

At present the Transcaucasus immigrants are working mostly in the sector of trade and services (realtors, market vendors, taxi drivers, drivers of minibuses, or owners of their own business), a small number (around 35\% of Armenians) are working in the construction sector.

The main motive for migration (permanent as well as temporary) of $90 \%$ of representatives of these ethnic groups would be the improvement of their financial situation ("earnings"), however, at the same time most respondents $(47,6 \%)$ have mentioned another significant motive for migration into the Moscow region - the "prestige".

The question about the place of residence in Moscow and Moscow region was answered 
differently than in case of Central Asia immigrants - most immigrants of this ethnic group have been living with relatives and $28,6 \%$ of respondents during the half year of living in Moscow region have acquired their own apartments.

It is interesting to note that answering the question about the time of residence in Moscow and Moscow region all the respondents have answered - "permanently".

To the question about the specifics of attitude of native population to the immigrants following answers have been given: "good" attitude was indicated by $42,9 \%$ of respondents; "supportable" - by $42,9 \%$ of respondents; and "bad" - by 14,2\% of respondents.

The question about their attitude towards the native population was answered as follows: $57,1 \%$ of immigrants believe their attitude towards the native population has been "good"; "supportable"-indicated by $42,9 \%$ of respondents.

Thus, there we have a rather different picture of inter-ethnic relationship of native population with the Transcaucasus immigrants, from the point of view of the latter. It can be noted that more than a half of immigrants have featured a rather low level of satisfaction with relationship with representatives of the receiving party.

Let us proceed to the results of questionnaires in connection with the perception of inter-ethnic relationship of native population with immigrants from North Caucasus (Dagestanis, Chechens, and Ingush).

The undertaken evaluation of data in connection with educational and professional level of immigrants has demonstrated the following facts. It has been defined that among the total number of immigrants from North Caucasus there was a clear differentiation of respondents with high education (legal, construction etc.) (around 45,6\%) and the vocational secondary education $(24,3 \%)$, as well as respondents studying in high education institutions (30,1\%).

At the moment the immigrants from North Caucasus are working mostly at the sectors of construction and business, and in governmental institutions (mostly the police authorities).

The main motive for migration (permanent as well as temporary) of $40 \%$ of representatives of these ethnic groups has been the improvement of the financial situation (“earnings”), another $40 \%$ respondents have mentioned the "career building", $14 \%$ of respondents have considered another significant motive for migration such as "prestige", and approximately the same number of immigrants (16\%) have explained the reason of their migration as "terrorist acts" (i.e. pursuance of safety).

The answers to the question about the place of living in Moscow and Moscow region have evidenced that the vast majority of immigrants had been living with relatives and $28,6 \%$ of respondents have during the half year of living in Moscow region have acquired their own apartments.

It is notable that answering the question about the time of residence in Moscow and Moscow region all the interviewed respondents have answered - "permanently".

To the question about the specifics of attitude of native population to the immigrants following answers have been given: "perfect attitude" - 10\% of respondents; "good attitude" was mentioned by $32,9 \%$ of respondents; "supportable" - 42,9\% of respondents; "bad" attitude $-14,2 \%$ of respondents.

The question about their attitude towards the native population was answered as follows: $20 \%$ of immigrants believed that their attitude towards the native population was "perfect"; the same number of respondents has answered "good" and $60 \%$ of respondents have indicated that their attitude was "supportable".

Generalizing the obtained results it can be pointed out that among all represented ethnic groups the most number of immigrants with low level of satisfaction towards the native population has been registered in the respondent sample from North Caucasus.

During the empirical study we have used the method of express-diagnostics of inter-ethnic acculturation by J. Berry, which enabled us to receive the data about the peculiarities of interactions of immigrants with the receiving multicultural society.

The vast majority of representatives of "problem" ethnic groups have been using the separation strategy, which is characterized by distancing from the behaviourial samples (way of living etc.) imposed by the dominating group, with preservation of one's own ethnic identity and traditions. 
The integration strategy, when the immigrants, from one side, should be trying to preserve a certain social and cultural integrity of their groups, and, from another side, should endeavour to become an integral part of a large social society, would be characteristic to immigrants of these ethnic groups to a lesser degree. For better illustration we have intentionally included the indexes of prevailing acculturation strategies of representatives of such ethnic group as the Armenians. With this it should be noted that the dominating strategy of Armenian immigrants shall be the integration one, which implies the preservation of one's cultural identity and joining the receiving society.

Such acculturation strategies as "assimilation", implying the negation of one's cultural identity and traditions and the acceptance of social and cultural identity of the receiving society; and "marginalization", leading to the loss of cultural and psychological contact with both native and receiving cultures by the ethnic groups, are presented insignificantly with the immigrants.

Using the methods of statistical processing and, in particular, the Fisher-test, there has been calculated the level of significance of differences in the choice of such acculturation strategies as integration and separation. Please see the obtained coefficients in Table 3.

Thus, basing on the statistical analysis, we can state that young immigrants from the "problem" ethnic groups would choose significantly more often (at $1 \%$ level of significance) the strategy of separation; whereas the young people from a non-"problem" ethnic groups (Armenians) would demonstrate a greater readiness to the integration (significant at $1 \%$ level of significance).

Results of research of the level of development of interethnic intolerance in the members of ethnic community organizations

The next stage of the research has become the definition of level of development of interethnic intolerance in the members of ethnic community organizations and other representatives of national minorities.

There have not been found any significant differences in the indexes of level of development of interethnic intolerance between the two research groups - members of the ethnic community organizations and representatives of relevant ethnic groups not belonging to any ethnic unions. Most of the interviewees of both the first and the second groups have been characterized by the average level of development of interethnic intolerance as the personality's feature.

It is specific that the indexes of development of positive ethnic identity, the balanced type of ethno-civil identity and civic responsibility do not differ from each other on the level of significant differences. We could only postulate the emerging tendencies of formation of these personality characteristics among the members of ethnic community organizations.

This fact evidences that the peculiarities of ethnic identification of members of ethic community organization would to a large extend depend on the peculiarities of their functioning.

Determination of such peculiarities has been realized during the second series of the empirical study. The study concentrated on the motives of uniting of representatives of ethnic minorities into relevant ethnic community organizations, and their needs; the level of their ethnic and civil identities, peculiarities of the autoand hetero-stereotypes, their subjective and interpersonal relationships, and the level of solidarity and value-orientation unity of the organization, the level of its development as a group entity.

The total number of the ethnic community organizations under this study has amounted to 502, 3930 people were interviewed representatives of the Germans, the Jews, Slavic people, people of North Caucasus, Transcaucasus, and people of the North and the Fat East.

The results of such study have enabled us making the following conclusions.

Firstly, the types of entering the ethnic community organizations may be direct as well as indirect. The direct type shall be characterized by the adequacy and consciousness of individual's choice of the content and orientation of its socially useful voluntary activities.

It is essential to note that the percentage distribution of the interviewees by the types of their ethno-civil identity evidences the prevailing crisis and conflict types; whereas the distribution by the types of ethnic identity - the positive and hyper-identity ones. 
This fact reflects the incongruence between the actual way of functioning of the ethnic community organizations and their potential possibilities and socially important missions as the institutions of a civil society.

Basing on the results of the content analysis of respondents' answers in connection with the purposes and motives of their entering the ethnic community organizations there have been defined the personal, social and familyconditioned motives.

Results of the following study allows us making a statement that the efficiency of activities of the ethnic community organizations would depend, first of all, on their type, representing the level and the features of development of interethnic identity of its members, which directly determine the level of inter-ethnic intolerance as the index of possible formation of nationalist ideas and sentiments in national minorities.

\section{DISCUSSION}

The features of functioning of the ethnic community organizations in connection with their orientation and content may be characterized by a dysfunctionality manifesting itself in the distortion of development of the ethnic self-identity in its members, motivational and axiological deformation of spheres of their personality, the lack of socially significant purposes and adequate necessities and personal senses.

It is of interest the results of correlation analysis which has revealed the direct correlation between the level of manifestation of a positive ethnic identity and the level of the subjective satisfaction with life $(r=0,212, p<0,05)$ and the inverse correlations with the level of social frustration $(r=-0,217, p<0,05)$ and the subjective feeling of loneliness $(r=0,234, p<0,05)$. However, such correlations have also been revealed with the indexes of level of manifestation of hyperidentity.

The results of correlation analysis allow us making the conclusion that the activity of a representative of ethnic minorities in a relevant ethnic community organization would ensure them a psychological well-being; however, it would not guarantee a socially valuable activity of an organization itself.
According to the correlation analysis, the level of manifestation of the isolating type of ethnocivil identity would correlate positively with the level of social frustration $(r=0,384, p<0,01)$, subjective feeling of loneliness $(r=0,313, p<0,01)$, the level of expression of personal neurotic disorders $(r=0,243, p<0,05)$ and the level of personal $(r=0,213, p<0,05)$ and situational $(\mathrm{r}=0,303, \mathrm{p}<0,01)$ anxiety; and would have a negative correlation with the indexes of level of adequate personal self-assessment $(r=-0,423$, $\mathrm{p}<0,001)$ and general satisfaction with life $(\mathrm{r}=$ $0,368, p<0,01$ ). There has also been found a close correlation between the indexes of isolating type of ethno-civil identity and the indexes of level of development of inter-ethnic intolerance as a personal feature $(r=0,446, p<0,01)$ and civic responsibility $(r=-0,564, p<0,001)$, which evidences a potential social risk of development in a representative of ethnic minority of such personality features as the type of immigrant that retains a sense of resentment for a involuntary residence in a foreign country.

The study of the orientation and the conscious purposes and content of an activity allows us speaking about various types of modern ethnic community organizations identified through the cluster and the subsequent factor analyses (Picture 1).

In terminology of the identified clusters we have based on the criteria of value-orientation unity of the investigated organizations, their level of solidarity, the degree of manifestation in the organization of the collective properties as a group subject of activity, the percentage of members of organizations with different levels of development of ethnic and ethno-civil identity and civic responsibility.

According to the identified factor structures of different types of ethnic community organizations we may conclude that $10,36 \%$ of organizations have had the characteristics of diffused charismatic type. The distinctive characteristic of such organizations shall be the lack of a single object of joint activities, low level of solidarity of the collective, blurred boundaries of the organization, and the lack of stable relationship among its members. The membership of such organizations shall be represented mostly by the individuals with the indifferent type of 
ethno-civil identity and low level of manifestation of the ethnic component of personality.

$9,16 \%$ of the investigated organizations have been attributed to the noncollineardissonant type, which is characterized by the extremely opposite purposes and motives of activity of members of the organization, the existence of antipathy among them, conflictive relationships and low level of solidarity, sociability, collectivism and information awareness.

Most of the investigated ethnic community organizations (56,57\%) have been characterized by the features of the consonantcreative type, implying the interest of their members in the development of folk art, the preservation of ethnic culture, national traditions and customs, and their promotion among the title (Russian) population. The membership of such organizations is represented by the creatively oriented individuals, interested in the success of their joint creative activity. Such organizations may feature various levels of development of collectivist relationship: from low to high. However, the consonance of the activities of such organizations shall be achieved through the value-orientation unity of their members, the coincidence of their views, opinions and relations, their positive ethnic identity and, as a rule, the average level of development of civic responsibility.

The difference between the consonantcreative type of ethnic community organizations from the balanced-constructive type shall consist in the content of the activity itself and in the awareness of its objectives and role in the development of a civil society. While the principal purpose of an ethnic community organization of the consonant-creative type shall be a folk art, the range of challenges for the members of a balancedconstructive type of ethnic community organizations shall be broader and would include the socially significant activities for harmonization of interethnic relations in the region, not only through the development of ethnic identity among representatives of the ethnic group and assisting them in adaptation to a foreign cultural environment, but also the formation of the sense of homeland, civil debt and civil responsibility. The assigned tasks shall be solved by the individuals who would generally feature the high level of development of the balanced ethno-civil identity. In this study only
$12,95 \%$ of overall number of the investigated organizations have attributed to this type.

A high level of solidarity shall also be characteristical for another two types of ethnic community organizations: consolidated confrontational and the consolidated destructive.

Consolidated-confrontational type of ethnic community organizations (5,38\%) features the tendency of their members to defend the interests of ethnic minorities, with this the implementation of the idea of fighting for the rights of a particular ethnic group shall be carried out by the individuals who would be characterized not only by a high degree of ethnic identity, but also the hypo-identity and generally a conflictive or crisis type of the ethno-civil identity, which implies a low level of development of civic responsibility and civic duty.

Consolidated-destructive type of ethnic community organizations (5,58\%) features the rigid internal and external borders, blurred purposes of its activities which would usually be destructive and carried out by the individuals with a hyperethnic identity and distorted national consciousness, up to the ethno-fanaticism. For this organizational type a high level of solidarity and low level of responsibility shall be characteristical. Prevailing ethnic interests against personal interests, justification of any sacrifices in struggle for the wellness of one's country in most members of such organizations shall be combined with an isolating type of ethno-civil identity, undeveloped sense of civic duty and civic responsibility for the consequences of one's actions and performance.

The results of the second series of the empirical study have also allowed the identification of the level of efficiency of functioning of modern ethnic organizations. Such investigation has been conducted through the method of expert evaluation of the results of activities of the organizations. Using the elaborated criteria-evaluation system there has been developed the form of expert evaluation, which was completed by five independent experts representatives of the administration interacting with the investigated ethnic community organizations. According to the expert results, $11,55 \%$ of the organizations have featured the dysfunctionality, 36,65\% - the mobile-unstable level of their efficiency; $25,29 \%$ - the stable one; $15,74 \%$ - the constant, and only $10,77 \%$ have demonstrated 
the constant-creative level of efficiency.

\section{CONCLUSIONS}

Essentially, the ethno-civil personal identity is a balance between the individual and social values of a person; the respect, acceptance and a concept of oneself as the bearer of a certain culture, combined with a high level of responsibility for the country in which the individual should be developing and improving. This is the consciousness by an individual of its inclusion and belonging to a certain social community, which is forming a part of a larger community with a complex combined system of connections and interrelations; this is such attitude and experience of a person associated with belonging to one's ethnos and one's country in general.

The results of the conducted study demonstrate, first of all, that the development of ethno-civil identity in members of ethnic community organizations shall be essential prerequisite for the prevention of the emergence of neo-fascist sentiments in a modern multicultural society.

In order to maintain the stability of functioning of the society and its national security it is necessary to develop and test the effective models of development of ethno-civil identity, resulting in a socially acceptable type of ethnic social organization.

\section{ACKNOWLEDGMENTS}

This article has been prepared within the grant of Russian Foundation for Humanities; Project .15-06-10966

\section{REFERENCES}

1. Alexandrenkov, E.G., Ethnic self-comprehension or ethnic identity // Ethnographic review, 1996; 3: 13-23.

2. Baklushinsky, S.A., Orlova, N.G., Features of formation of ethnic identity in a metropolis // Ethnos. Identity. Education, 1998; 248-267.

3. Belozerova, M.V., Regional national community organizations within the structure of civil society // Scientific dialogue, 2013; 6(18): 137-150.

4. Bonkalo, T.I., Kolesnik, N.T., Varavina, L.V., State and public regulation of migration processes in the modern Russia: psychological aspect. - M.: AIM, 2015; 225.

5. Bromley, Y.V., Essays on the theory of ethnos / Y.V. Bromley; postscript by N.Y. Brompley. $2^{\text {nd }}$ edition, add. - M.: Editorial LKI, 2008; 5758.

6. Buchek A.A., Ethnic personal self-identity in multi-ethnic world environment: Monography. - Petropavlovsk-Kamchatsky: KamSU named by Vitus Bering., 2012

7. Drobizheva, L.M., The problems of inter-ethnic relations in the post-Soviet Russia // Social transformations in Russia. M.: Flinta, 2005; 194222.

8. Gumilev, L.N., Ivanov, N.G., Ethnic processes: two study approaches // Sotsis, 1992; 1: 14-24.

9. Krysko, V.G., Ethnic psychology. - M.: Academia, 2002.

10. Kurinskyh, P.A., Culture of life sustaining as the object of ethnological expertise // Applicable ethnology and actual problems of the state ethnic and national policy in the Western Siberia regions: mechanisms of interaction of the government, science, and society. - Kemerovo: Practika, 2013; 83-87.

11. Lebedeva, N.M., Introduction to the ethnic and cross-cultural psychology. - M.: Academia, 1999.

12. Miller, A.I., Nationalism as the theoretical problem (Orientation in a new research paradigm) // Polis, 1995; 6: 12-25.

13. Pochebut, L.G., Mutual understanding of the cultures: the psychology of inter-ethnic tolerance. - SPb.: SPbSU, 2005.

14. Sadovoy, A.N., Basic factors of formation of the protectionist national policy in the SouthSiberian region (XVIII-XIX centuries) // The problems of archeology, ethnography, and anthropology in Siberia and the adjacent territories. - Novosibirsk: IAiE SB RAS, 1998; 4: 461-465.

15. Skobelina, N.A., Modern community organizations and society movements // Volgograd State Technical University bulletin, 2005; 4: 48-50.

16. Soldatova, G.U., The psychology of inter-ethnic tension. 1997;

17. Stefanenko, T.G., Ethno-psychology: practicum. -M.: Aspect Press, 2008.

18. Tishkov, V.A., Shabaev, Y.P., Ethno-politology: political functions of ethnicity. M.: MSU, 2011.

19. Yuriev, S.S., Legal status of national minorities (theoretical and legal aspects). - M.: Editorial URSS, 2000; 259.

20. Zdravomislov, A.G., Ethno-political processes and dynamics of national self-identity of Russian people // Sotsis, 1996; 12: 64-68 